\title{
Conflicts of interest in genetic counseling: acknowledging and accepting
}

\author{
Katie A. Stoll, MS, CGC1, Amanda Mackison, MPP1, Megan A. Allyse, PhD² and Marsha Michie, PhD³
}

Conflicts of interest (COI) in clinical practice have garnered attention in recent years, prompting a flurry of institutional and governmental policies to prevent both professional misconduct and the public perception of misconduct. Although most concerns focus on financial COI that may compromise patient care, $\mathrm{COI}$ in the more general sense are ubiquitous and often unavoidable. The Institute of Medicine has defined conflict of interest as "a set of circumstances that creates a risk that professional judgment or actions regarding a primary interest will be unduly influenced by a secondary interest." They further clarify that conflict of interest "is not an occurrence in which primary interests are necessarily compromised. ... A conflict of interest exists whether or not a particular individual or institution is actually influenced by the secondary interest." ${ }^{\prime \prime}$

Every one of us navigates COI in our everyday life-professional priorities often conflict with personal ones, clinicians' with those of patients, and employees' with those of employers. When we discuss these conflicts-if we discuss them-we frequently soften the language we use and speak of "perceived conflicts." Although comforting, this language is misleading. It is important to recognize that COI are not simply a matter of perception. We may legitimately debate the influence COI have in particular situations, but they are an objective reality that can be defined and assessed.

Recently, the objectivity of genetic counselors in some professional situations has been called into question, citing financial ties to industry. ${ }^{2,3}$ In response, the National Society of Genetic Counselors (NSGC) referenced its code of ethics, which advises members to keep in mind relationships that could undermine patient care. ${ }^{4}$ As genetic counselor Robert Resta has astutely pointed out, it is difficult for people who view themselves and their profession as being on ethically high ground to see that a conflict of interest could affect their behavior. ${ }^{5}$ Indeed, because the profession of genetic counseling is built on assisting patients in making decisions that best suit their personal needs and values, implying that genetic counselors may have conflicts of interest seems to strike at the heart of the profession's integrity and identity. Yet, for this same reason, it is crucial that genetic counselors acknowledge that they, like all medical professionals, can and do have COI, and work to manage them.
The profession of genetic counseling is relatively young; the first graduate training program was established in 1969. For the first few decades of its existence, genetic counselors were primarily employed in academic medical centers, working with physicians in the areas of reproductive genetic risk assessment and genetic testing; in pediatric clinics when families were faced with a new genetic condition in a child; and, in the late 1990s, in the setting of oncology with regard to hereditary cancer. However, in the 1990s, with new discoveries leading to new opportunities in molecular diagnostics, genetic testing began to move from academic medical centers and not-for-profit laboratories into for-profit corporate laboratories. ${ }^{6}$ This increasing commercialization expanded employment opportunities for genetic counselors, which combined with ongoing challenges in receiving insurance reimbursement for genetic counseling services, ${ }^{7}$ led to a gradual shift toward commercial laboratories as a leading employer of the United States' more than 4,000 certified genetic counselors.

With increasingly diverse employment opportunities have come questions regarding COI. COI in medicine are, of course, neither new nor exclusive to genetic counselors. The 2010 Physician Payments Sunshine Act, for example, requires that pharmaceutical companies publicly report incentive payments to physicians that may generate a COI. ${ }^{8}$ These policies have increased transparency and highlighted the challenges of $\mathrm{COI}$ in medicine. However, these laws do not extend to genetic counselors or to most companies that develop and sell genetic tests; the Sunshine Act focuses largely on pharmaceutical and medical device manufacturers' relationships with physicians. For example, the Sunshine Act (had it existed at the time) would not have applied to Myriad Genetics's training of genetic counselors in the late 1990s and early 2000s to provide direct patient counseling regarding its BRACanalysis testing for hereditary breast cancer risk and their employment of more than 20 genetic counselors to train physicians to counsel patients about the test practices, both of which raise obvious COI. ${ }^{9}$

Another concern is the practice of industry-employed genetic counselors providing direct patient care within clinics and via telehealth. This practice has caused concern because the interests of a commercial laboratory are not always in

${ }^{1}$ Genetic Support Foundation, Olympia, Washington, USA; ${ }^{2}$ Biomedical Ethics Program, Mayo Clinic, Rochester, Minnesota, USA; ${ }^{3}$ Institute for Health \& Aging, University of California, San Francisco, San Francisco, California, USA. Correspondence: Marsha Michie (marsha.michie@ucsf.edu) 
alignment with medical professional guidelines. Although practice guidelines are designed to weigh the risks versus benefits of expanding the number of screens and tests offered in the prenatal period-for instance, population-based screening for Fragile $\mathrm{X}$ is still not recommended ${ }^{10}$ - commercial testing companies have a stated interest in expanding the number of tests that are ordered. As an employee of the company, a genetic counselor thus has two interests: following practice guidelines and benefiting their employer. These two interests are not always in conflict, but the potential exists. And while commercial laboratories may highlight genetic counseling by a laboratory-provided genetic counselor as a value-added service benefiting patients, it may not always be obvious to patients that they are receiving genetic counseling from an employee of a genetic testing company.

Although pretest genetic counseling raises concerns, posttest counseling by industry-employed genetic counselors can also be problematic. Several genetic testing laboratories actively advertise the availability of genetic counseling as an incentive to use their brand of testing. Recipients of these services, however, have called into question whether genetic counselors employed by commercial laboratories are as open to discussing the potential weaknesses and failures of the test as they would be if they were independently employed. Furthermore, promoting ease of genetic counseling to market new genetic tests may promote inappropriate test utilization; providers may be encouraged to order testing beyond their understanding and expertise because they feel they can rely on the laboratory-based genetic counselors to address any issues that may arise. ${ }^{3}$

We recognize that genetic counselors employed by laboratories are likely no less focused on providing the best, professionally responsive care than any other genetic counselor, but the reality is that COI exist, regardless of whether they cause clinicians to act against patients' interests. Furthermore, the discovery of COI after the fact can seriously undermine patients' trust, not just in an individual genetic counselor but in the entire biomedical infrastructure surrounding genetic testing. A crucial first step is transparency. At the profession-wide level, documentation of the employment status of genetic counselors through the annual status survey should include not only "work setting," as it now does (http://www.nsgc.org/page/whoaregeneticcounselors), but also the source of employment-in order to reflect the increasing numbers of laboratory-employed genetic counselors who provide direct patient counseling outside of laboratories. This distinction has already been recognized by some insurers, which mandate (and reimburse) genetic counseling only by a non-laboratory employed genetic counselor for certain covered genetic tests. ${ }^{11}$ Insurance coverage for genetic counseling may play an increasing role in the employment options of certified genetic counselors as genetic information is increasingly integrated into clinical care.
At the individual level, disclosure of financial COI should be mandatory for board-certified genetic counselors in clinical practice, as it is for physicians. Although the Sunshine Act does not provide a legal mandate for such disclosures, it does offer a clear example and a model that could be implemented by the NSGC and/or the certifying body for genetic counselors, the American Board of Genetic Counseling (ABGC). Unfortunately, without the legal mandate this model would require accurate self-reporting by genetic counselors about their COI. The profession would also need to decide how to disseminate this information; the database of Sunshine Act disclosures maintained by the Center for Medicaid Services is one model, but it has been critiqued for both its content, which may not adequately parse the types of payments physicians receive from companies, and its structure, which requires that patients seek out this information online and decide for themselves what it may mean. ${ }^{8,12}$ However, such disclosures could result in a publicly accessible database of COI reports that would enable the NSGC, the ABGC, and/or healthcare institutions to implement responsible policies for assessing and mitigating COI. Mitigation strategies for circumstances of COI might include limits on the types of counseling provided (e.g., support to health-care providers rather than direct patient contact), the content of provider education and consultation (e.g., review of educational materials by independent experts), increased transparency in reporting of COI by genetic counselors (e.g., mandated disclosure of laboratory employment or compensation before providing education and support to health-care providers), or other strategies appropriate to individual circumstances. Such policies will not prevent undue influence of COI in all cases but would prove invaluable in raising awareness of COI among genetic counselors and in safeguarding the trust patients have placed in this young profession.

\section{ACKNOWLEDGMENTS}

M.M. is supported by NIH grant R0OHG006452.

\section{DISCLOSURE}

The authors declare no conflict of interest.

\section{REFERENCES}

1. Institute of Medicine (US). Committee on Conflict of Interest in Medical Research E, and Practice. Conflict of Interest in Medical Research, Education, and Practice. National Academies Press: Washington, DC, 2009. http:// nationalacademies.org/hmd/reports/2009/conflict-of-interest-in-medicalresearch-education-and-practice.aspx. Accessed 13 January, 2017.

2. Daley B. When baby is due, genetic counselors seen downplaying false alarms. Boston Globe 6 March 2016.

3. Pollack A. Before birth, dad's ID: paternity blood tests that work early in a pregnancy. New York Times 19 June 2012. http://mww.nytimes.com/2012/06/20/ health/paternity-blood-tests-that-work-early-in-a-pregnancy.html? $r=2 \& n l=a f t e r n o o n u p d a t e \& e m c=e d i t \_a u \_20120619$. Accessed 13 January, 2017.

4. Daley B. After angry moms fault counseling, genetics society cites its ethics code. The Eye. 11 March 2016. https://eye.necir.org/2016/03/11/after-angry-momsfault-counseling-genetics-society-cites-its-ethics-code. Accessed 13 January, 2017. 
5. Resta R. Appearances are important. The DNA Exchange. 25 April 2016. https://thednaexchange.com/2016/04/25/appearances-are-important/. Accessed 13 January, 2017.

6. Natowicz MR, Ard C. The commercialization of clinical genetics: an analysis of interrelations between academic centers and for-profit clinical genetics diagnostics companies. J Genet Couns 1997;6:337-355.

7. Harrison TA, Doyle DL, McGowan C et al. Billing for medical genetics and genetic counseling services: a national survey. J Genet Couns 2010;19:38-43.

8. Richardson E. Health Policy Brief: The Physician Payments Sunshine Act. Health Affairs. 2 October 2014. http://www. healthaffairs.org/healthpolicybriefs/brief. php?brief_id=127. Accessed 13 January, 2017.
9. Gold ER, Carbone J. Myriad Genetics: in the eye of the policy storm. Genet Med 2010;12(4 suppl):S39-S70.

10. American College of Obstetricians and Gynecologists. Carrier screening for fragile X syndrome. Committee opinion no. 469. Obstet Gynecol 2010;116:1008-10.

11. Swanson A, Ramos E, Snyder H. Next Generation sequencing is the impetus for the next generation of laboratory-based genetic counselors. J Genet Couns 2014;23:647-654.

12. Lenzer J. Two years of sunshine: has openness about payments reduced industry influence in healthcare? BMJ 2016;354:14608. 